\title{
Toxoplasma gondii infection in humans in China
}

\author{
Peng Zhou ${ }^{1,2}$, Zhaoguo Chen ${ }^{2}$, Hai-Long Li ${ }^{1,3}$, Haihong Zheng ${ }^{4}$, Shenyi He ${ }^{5}$, Rui-Qing Lin ${ }^{3}$ and Xing-Quan Zhu ${ }^{1,6,7^{*}}$
}

\begin{abstract}
Toxoplasmosis is a zoonotic infection of humans and animals, caused by the opportunistic protozoan Toxoplasma gondii, a parasite belonging to the phylum Apicomplexa. Infection in pregnant women may lead to abortion, stillbirth or other serious consequences in newborns. Infection in immunocompromised patients can be fatal if not treated. On average, one third of people are chronically infected worldwide. Although very limited information from China has been published in the English journals, T. gondii infection is actually a significant human health problem in China. In the present article, we reviewed the clinical features, transmission, prevalence of T. gondii infection in humans in China, and summarized genetic characterizations of reported $T$. gondii isolates. Educating the public about the risks associated with unhealthy food and life style habits, tracking serological examinations to special populations, and measures to strengthen food and occupational safety are discussed.
\end{abstract}

Keywords: Toxoplasma gondii, Epidemiology, Human, Infection, China

\section{Background}

Toxoplasmosis, a cosmopolitan disease in humans and most mammals, is caused by the opportunistic protozoan Toxoplasma gondii mainly through peroral infections, bloodstream infections and congenital acquired infections. It has been estimated that one third of the world population has been infected [1,2]. In most adults it does not cause serious illness, however, blindness and mental retardation can be caused in congenitally infected children and severe diseases in those with compromised immunity. A recent study indicated that infection with T. gondii is associated with abdominal hernia [3].

Toxoplasma gondii needs both definitive hosts and intermediate hosts to complete its sexual and the asexual replication phases in life cycle. The sexual phase only occurs in the intestine of the definitive hosts, felids. All the warm-blooded animals, the intermediate hosts, become infected mainly by consuming food or drink contaminated by oocysts evacuated from felids and tissue cysts from other intermediate hosts [4]. Acute infection happens in the initial few days, with the rapidly growing replication of the tachyzoites. Tachyzoites switch to bradyzoites as time goes by and form tissue cysts parasitizing

\footnotetext{
* Correspondence: xingquanzhu1@hotmail.com

'State Key Laboratory of Veterinary Etiological Biology, Key Laboratory of Veterinary Parasitology of Gansu Province, Lanzhou Veterinary Research Institute, Chinese Academy of Agricultural Sciences, Lanzhou, Gansu Province 730046, P R China

Full list of author information is available at the end of the article
}

in host cells. It would be lethal in Toxoplasma infected immune-compromised patients if bradyzoites revert to tachyzoites. In addition to felids, intermediate hosts carried with tachyzoites or tissue cysts are also responsible for the spread of $T$. gondii. Peroral infection, congenital and blood infection are three major ways for the transmission of this parasite [5].

The first human case of toxoplasmosis in China was report in 1964 in Jiangxi Province [6]. Many human cases were reported in China since the first epidemic survey on toxoplasmosis was carried out in Guangxi Province in 1978 [7]. However, toxoplasmosis cases in China are hardly recognized by western clinicians, for very little information from China was published in English. The rising prevalence of $T$. gondii infection and the increasing clinical cases [8-10] in immunocompromised patients, and patients with congenital toxoplasmosis and psychosis should draw our attention to address toxoplasmosis as a serious public health problem. It is thus timely and appropriate to review the Chinese literature on Toxoplasma and toxoplasmosis to gain an improved insight into its epidemiology and socioeconomic impact in China. Most of the data quoted in this review were derived from articles published in Chinese on T. gondii infection in humans up to 2011, obtained from The China National Knowledge Infrastructure (CNKI) database via its website http://www.cnki. net, using the keywords "Toxoplasma", "Toxoplasmosis" and "Epidemiology". We intend to provide clinical information, to summarize some key aspects regarding 
transmission and prevalence of human toxoplasmosis, and genetic characterizations of T. gondii strains in China, and to conclude by making some suggestions for further research and recommendations for the prevention and control of this important human protozoan disease.

\section{Epidemiology}

Between 2001 and 2004, the national serological survey of 47,444 people in 15 provinces and autonomous regions estimated a mean prevalence of $7.9 \%$ by using enzymelinked immunosorbent assay (ELISA) [11]. Prevalence in these provinces has increased from $5.2 \%$ in the first national survey conducted between 1988 and 1992 [12]. Though a recent serological survey carried out in 3281 individuals from the northeast and the south of China showed a $12.3 \%$ anti- $T$. gondii IgG positive rate, which indicated the increasing growth in prevalence [13], the prevalence of $T$. gondii in China was still relatively low, comparing with $50-75 \%$ seropositive in France, and 20\% in UK [14].

Guizhou province and Guangxi province had the highest levels with prevalence of $15.1 \%$ and $12.7 \%$, respectively [15]. Prevalence in Miao (25.4\%), Buyi (25.3\%), Mongol (17.1\%) and Zhuang (16.7\%) ethnic groups are higher than in other groups of the population [15]. Eating habits play an important role in the parasite infection. People living in southwest of China enjoy eating raw or half-raw meat or animal internal organs in their tradition, such as the 'Sour-meat' (let raw pork or beef ferment and become sour), the 'Shengpi' (is a cooking method which keeps pork and beef half-raw), and even raw pig or cattle liver $[16,17]$. The Mongol people like to eat their traditional food 'Mongolian Finger Mutton' by hands after contact with animals or raw meat without appropriate washing procedures, because of the water shortage in their living areas, which could lead to Toxoplasma infection, in addition to other food-borne diseases such as taeniasis, cysticercosis, trichinelliasis and echinococcosis [15].

\section{Human toxoplasmosis in mainland China Immunocompromised patients with toxoplasmosis}

Toxoplasmosis can be life-threatening in immunocompromised patients as a result of reactivation of chronic infection. High seroprevalence of latent $T$. gondii infection has been found among immunocompromised patients. Prevalence of $T$. gondii infection in cancer patients ranged from 24\% [18] to 79\% [19]. Prevalence of T. gondii infection varied with different cancers. Rectal cancer and nasopharyngeal carcinoma sufferers in Changchun city had the highest infection, with prevalence of $63.6 \%$ and $46.2 \%$, respectively [18]. However, T. gondii infections in patients with breast cancer, hepatocellular carcinoma and gastric carcinoma in Henan Province were much higher than with other cancers, with a prevalence of $78.9 \%, 77.8 \%$ and
$61.1 \%$, respectively [19]. The average prevalence of T. gondii infection was $15.1 \%$ in leukemia patients. Moreover, $T$. gondii prevalence in refractory cases of leukemia patients was up to $35 \%$ [20].

Surveys of T. gondii infection in the individuals with tuberculosis and hepatitis B showed that the prevalence were $35.3 \%$ [21] and 19.3\% [22], respectively. Most of the cases belonged to chronic infections. $70 \%$ of individuals infected with $T$. gondii and tuberculosis had the experience of intimate contact with animals [21]. Similarly, high prevalence of $T$. gondii infection have been detected among immunocompromised patients especially suffering from malignancy in Egypt and Korea [23,24]. Although there is no direct association between the susceptibility of toxoplasmosis and the immunocompromised state, the high seroprevalence in immunocompromised patients indicates considerable risks, because toxoplasmosis is a consequence of recrudescence of a previously latent infection in most immunocompromised patients, with the chronic parasite infection activation after the immune system was damaged [25].

The first case of AIDS patient died in China was reported in 1991, and T. gondii was found in the cerebellum of this patient [26]. In a more recent report, 26\% of HIV infected patients in Xinjiang were seropositive with T. gondii infection [27].

The CNS is the site most typically affected by $T$. gondii infection. A series of clinical manifestations including mental status changes, seizures, focal motor deficits, cranial nerve disturbances, sensory abnormalities, cerebellar signs, movement disorders, and neuropsychiatric findings have often been found among toxoplasmic encephalitis (TE) cases. The incidence of TE was from $0.6 \%$ [28] to 10.5\% [9] among the HIV infected patients in Henan and Yunnan Provinces, with all the $\mathrm{CD}_{4}{ }^{+} \mathrm{T}$-lymphocyte count below 100 cells per microliter. Toxoplasmic lymphadenitis and retinitis were also found in HIV-infected patients, with the incidence of $6 \%(2 / 33)$ [29] and 5.3\% (2/38) [9], respectively.

\section{Congenital toxoplasmosis}

Congenital infection caused by transplacental transmission can lead to a wide variety of manifestations in the fetus and infant including spontaneous abortion, still-birth, a newborn with classic signs of congenial toxoplasmosis such as hydrocephalus or microcephalus, cerebral calcifications and retinochoroiditis [30,31]. There were no national reports about congenital toxoplasmosis on newborns in China. Previous studies focused on certain areas with severe cases. The seroprevalence of $T$. gondii in newborns was between $4.4 \%$ to $19.4 \%$ in Huizhou city, Shantou city and Dalian city [32-34]. A survey of $T$. gondii infection in 80 puerperas and their new-born babies showed that the seroprevalence were $8.8 \%$ and $6.3 \%$, 
respectively. The vertical transmission was $70 \%$ by using ELISA, which was still serious in Xinxiang city of Henan Province [35].

Most infected newborns have no apparent physical abnormalities at birth, but without treatment, most of them may later develop chorioretinitis, neurologic damage or growth can be delayed later in life. The seroprevalence of $T$. gondii infection in disabled children with symptoms of hypophrenia, epilepsy, retinochoroiditis, cardiovascular defects and respiratory system defects were $21.7 \%, 20 \%$, $26.1 \%, 25 \%$ and $14.3 \%$, respectively [36]. A case-control study in Hainan Province, involving 79 cases of infantile cerebral palsy, revealed that the seroprevalence of $T$. gondii was $41.8 \%$, with significant difference $(P<0.001)$ from the 256 control cases with seroprevalence of $8.6 \%$ [37]. A survey of 592 congenital defect infants in Nanjing city, Jiangsu province revealed a $28.13 \%$ seroprevalence of T. gondii infection, which was significantly higher compared with the normal ones (0.6\%) [10].

\section{Ocular toxoplasmosis}

Ocular toxoplasmosis (OT) may induce more than 30\% posterior uveitis cases in western populations [38]. Even though both congenital and acquired infection may develop ocular lesions, it has been suggested that $70 \%$ of chorioretinal scar formation is of congenital origin [39]. Congenital ocular toxoplasmosis mainly causes congenital malformation, with anophthalmus, congenital aniridia, chorioretinal, congenital cataract, optic neuritis, strabismus, amblyopia, nystagmus, optic atrophy, visual field defects, etc. Ocular lesions originated from acquired infections occur after birth, which resulted in tissue destruction and inflammatory responses [40]. The first case of OT reported in China also was found in the first human toxoplasmosis case in Jiangxi Province in 1964 [6]. The incidence of OT in China is still unclear. The seroprevalence of OT in ophthalmocace patients was up to $38.8 \%$ [41]. Central exudative chorioretinitis and uveitis are the most common symptoms in OT cases reported in China $[42,43]$.

\section{Toxoplasmosis and schizophrenia}

Evidence is mounting to link toxoplasmosis with schizophrenia or similar psychiatric disorders. Recent studies revealed that levels of antibodies to $T$. gondii have been found to be increased in individuals with schizophrenia compared to controls with an odds ratio for Toxoplasma seropositivity between 2 and 4.4 [44-47]. In prospective studies, an increase in IgG antibodies to $T$. gondii has been found in mothers of infants who later develop schizophrenia [48].

Many reports revealed that Toxoplasma might represent a major pathogen in some cases of psychosis. It has been proven that the parasite infection could increase the dopamine level in mice brains [49]. Dopamine plays a key role in psychosis cases such as schizophrenia, and bipolar disorder [50-52]. The seroprevalence of $T$. gondii infection in schizophrenic patients ranged from $1 \%$ to $28.7 \%$ in China [11,53]. A report of 67 cases of childhood schizophrenia between 6 17 years old revealed a Toxoplasma-IgG positive rate of $85.7 \%$ [54]. Another survey on Toxoplasma infection in 600 cases of the first episode of schizophrenia revealed that the ToxoplasmaIgG positive rate was $13.7 \%$ [55]. The prevalence of Toxoplasma IgG in mothers of 252 was 34.8\% [55]. The alterations of behavior and psychomotor skills in schizophrenia patients have also been found to be associated with the T. gondii infection [56]. Compared with the seronegative ones, clinical manifestations of excitation, hostility, mannerisms and posturing, disturbance of volition, poor impulse control and anger, difficult to delay fulfilling request and suspiciousness in the seropositive patients were statistically different [56]. The schizophrenic patients living in rural area have a higher infection rate than these lived in cities, with prevalence of $28.6 \%$ and $6 \%$, respectively [57].

\section{Poor obstetric outcomes, sterility and toxoplasmosis}

There is as yet no direct evidence showing the association between toxoplasmosis and sterility in women. Nevertheless, some studies have demonstrated that $T$. gondii infection could cause reproductive failure in mice, which was due to an acquired hypogonadotropic hypogonadism secondary to hypothalamic dysfunction, exhibiting histopathological changes with estrus cycling cessation, impaired folliculogenesis and few corpora lutea [58,59]. It seems that $T$. gondii infection in pregnant women may cause poor obstetric outcomes such as spontaneous abortion, hydatidiform mole, still-born, teras and sterility. Women who had a poor obstetric outcome history had a seroprevalence of $14.2 \%$ [60] to $33.9 \%$ [61] which was much higher than that of the normal pregnancy in China. A survey of $T$. gondii infection in 68 cases of oviducal sterility revealed a prevalence of $44.1 \%$, which was significantly different from that in normal pregnant women (3.3\%) [62], indicating that Toxoplasma infection could result in oviducal sterility.

T. gondii infection is also found to be related with the male sterility. Recent zoopery studies revealed that the reproductive parameters including sperm motility and sperm concentration were significantly decreased in T. gondii infected rats, and a marked increase in sperm abnormalities was also found in these infected male rats [63]. Similar results were also observed in male mice experimentally infected with T. gondii [64]. Zhou (2002) [65] found that Toxoplasma infection in infertile human couples was higher than that in fertile couples, possibly related to the antisperm antibodies which were higher in 
Toxoplasma-infected couples. A recent investigation of T. gondii infection in 100 men with sterility revealed that $16 \%$ of them were IgM-positive and $13 \%$ were CAg-positive, significantly higher than in healthy men [66]. The seroprevalence of Toxoplasma infection in male sterility cases were $19.8 \%$ in Luoyang, Henan province [67], to $22.8 \%$ in Yan'an, Shaanxi province [68], significantly higher than in the healthy men. Based on a number of relevant studies and investigations in China, it is concluded that $T$. gondii infection may result in male sterility [69].

\section{Transmission of toxoplasmosis}

\section{Transmission by contact with animals}

Some occupations required people to have contact with animals and meats and these frequently possess higher risk of infection with the parasite, such as dairy workers, slaughterhouse workers, veterinarians, meat-processing workers, meat sellers and cooks. Selected serological surveys of $T$. gondii infection in different occupations in China are summarized in Table 1.

These data suggest that the oral route is the major route of infection. Pork is one of the most popular meats in China. Seroprevalence of T. gondii in pigs is high in some Chinese provinces, for instance $16.9 \%$ in Yunan province [76], 27\% in Guangdong province [77] and $53.4 \%$ in Zhejiang province [78], which are higher than that in USA (2.7\%, [79]), Germany (4.1\%, [80]) and Mexico $(12.7 \%,[81])$. There is still no meat inspection for T. gondii contamination in meat before it is sold for human consumption, nor any strict performance standards for processing meat and animal products, which gives a high risk of infection for these workers. Similar high prevalences of $T$. gondii infection have also been found in butchers in Finland [82], Egypt [83] and Brazil [84]. A latest Mexican report proposed that occupational exposure to raw meat has no correlationship with seropositivity of $T$. gondii infection [85]. The reason may be associated with good sanitary conditions in the slaughterhouses and powerful protective facilities to the workers. However, in our investigations of $T$. gondii infection in slaughter pigs in several provinces in China, we found that butchers do not always wear gloves during work because of the hot and humid environment around the slaughterhouses, which may increase the risk for T. gondii infection when handling raw meat.

Herdsmen possessed a higher $T$. gondii prevalence in the west China, such as Xinjiang and Inner Mongolia due to inadequate sanitary conditions and the traditional eating habits mentioned above, with seroprevalence ranged from $6.7 \%$ [86] to $18.5 \%$ [87]. People owning dogs and cats as pets also processed a high risk of infection, with the prevalence ranged from $5.3 \%$ [88] to $34.8 \%$ [74].

\section{Transmission by blood transfusion}

T. gondii can also be transmitted via blood or leucocytes from infected donors [89]. The seroprevalence of T. gondii in blood donors in China varied between $0.4 \%$ [90] to $20.2 \%$ [91], which were lower than in Egypt (59.6\%) [92] and Malaysia (28.1\%) [93]. Peasant blood donors had the highest seroprevalence $(28.6 \%)$, which may be related to the living habits and chances of contacting with animals [91]. Therefore, it is very urgent for a hospital to check all the blood from blood donors. It would be lethal to transmit the parasite from immunocompetent donors to immunocompromised recipients during surgery.

Another pattern of $T$. gondii transmission by blood is though needles among intravenous drug users (IVDU). The prevalence of $T$. gondii in IVDU ranged from $17.3 \%$ [94] to $21.8 \%$ [95], which were significantly higher $(P<$ 0.01 ) than the prevalence $(7.8 \%)$ in those who took drugs by the non-intravenous route [95]. Drug addiction history and HIV infection was associated with the susceptibility of Toxoplasma in IVDU. IVDU with 5 years or more

Table 1 Serological surveys of Toxoplasma gondii infection in people of different occupations in China

\begin{tabular}{|c|c|c|c|c|c|c|}
\hline Occupations & Year & Area and Province & Serologic test ${ }^{a}$ & No. tested & Positive & Reference \\
\hline \multirow[t]{2}{*}{ Slaughterhouse Workers } & 2003 & Haerbin, Heilongjiang & ELISA & 86 & $25.6 \%$ & {$[70]$} \\
\hline & 2005 & Anshun, Guizhou & ELISA & 100 & $45.0 \%$ & {$[71]$} \\
\hline \multirow[t]{2}{*}{ Dairy Workers } & 2004 & Guangzhou, Guangdong & ELISA & 459 & $10.2 \%$ & {$[72]$} \\
\hline & 2004 & Huadu, Guangdong & ELISA & 25 & $24.0 \%$ & {$[73]$} \\
\hline \multirow[t]{2}{*}{ Veterinarians } & 2002 & Lanzhou, Gansu & ELISA & 24 & $12.5 \%$ & {$[74]$} \\
\hline & 2005 & Anshun, Guizhou & ELISA & 100 & $26.0 \%$ & {$[71]$} \\
\hline \multirow[t]{2}{*}{ Meat-processing workers } & 2004 & Huadu, Guangdong & ELISA & 131 & $13.7 \%$ & {$[73]$} \\
\hline & 2005 & Anshun, Guizhou & ELISA & 100 & $21.0 \%$ & {$[71]$} \\
\hline \multirow[t]{2}{*}{ Cooks } & 1996-1999 & Wuxi, Jiangsu & ELISA & 627 & $29.7 \%$ & {$[75]$} \\
\hline & 2004 & Huadu, Guangdong & ELISA & 150 & $10.0 \%$ & {$[73]$} \\
\hline \multirow[t]{2}{*}{ Animal Breeder } & 2002 & Lanzhou, Gansu & ELISA & 25 & $20.0 \%$ & {$[74]$} \\
\hline & 2005 & Anshun, Guizhou & ELISA & 100 & $12.0 \%$ & {$[71]$} \\
\hline
\end{tabular}

${ }^{a}$ ELISA: enzyme-linked immunosorbent assay 
addiction history possessed higher seroprevalence compared with those less than 5 years, with seropositivity of $21.8 \%$ and $8 \%$, respectively [94]. Toxoplasma prevalence in drug users with HIV was significantly higher than in those with no HIV infection, being 35.8\% (29/81) and 5\%, respectively [94].

\section{Congenital transmission}

When a woman ingests oocysts or cysts of T. gondii for the first time during gestation [2], tachyzoites are disseminated through the body by blood. The fetus becomes infected by the entry of $T$. gondii to the fetal circulation though the placenta. Maternal acquisition of T. gondii before pregnancy poses a rare risk to the fetus except the infection in immunocompromised women [96]. The risk of congenital infection increases during pregnancy. The acquisition within the first pregnancy trimester has the lowest risk (10-15\%) of congenital infection, whereas risks of transmission are much higher during the third trimester [2]. Fortunately, the later in pregnancy that congenital infection occurs, the less severe the consequence is to the fetus.

Since more than $90 \%$ of chronic toxoplasmosis infections are asymptomatic, primary prevention is the best way to lower the risk of congenital infection. The detection and treatment of $T$. gondii in infected pregnant women would be an efficient way of attempting to reduce congenital transmission. In China, surveys of Toxoplasma infection in women were often been carried out before or at the third month of pregnancy. Selected serological surveys in women during pregnancy in different areas in China during 1994 to 2008 are summarized in Table 2. The prevalence of $T$. gondii infection in pregnant women ranged from $0.5 \%$ [106] to $25.5 \%$ [104] in China, which were lower than those reported in Austra (35\%) [113], France (43.8\%) [114] and Brazil (53.0\%) [115]. The cultural behaviors and living conditions play an important part for the parasite infection in pregnant women. Those pregnant women who had a history of contact with animals and had habits of consuming undercooked meat or some other raw foods such as unpasteurized milk or raw eggs, possessed a higher risk for infection.

\section{Genetic characterization of $T$. gondii strains}

The information on genetic characterization of $T$. gondii strains prevailing in China is limited even though there have been many reports of seroprevalence of $T$. gondii infection in humans and animals published locally in the Chinese language. But, only a small percentage of exposed humans or animals develop clinical toxoplasmosis, which increases the difficulty for parasite isolation. Based on 10 PCR-RFLP markers, the genetic variability of $T$. gondii isolates from China has been revealed gradually. A total of 5 genotypes were identified, indicating limited diversity of the parasite in China, which is in sharp contrast to South America where a variety of parasite lineages are transmitted in the environment [116]. Clonal Type I lineages were identified from human patients and pigs in China. The unique genotype in cats in Guangzhou city [117], has also been identified from human patients and pigs [116]. It is the major lineage prevalent in Mainland China, which has also been identified from Colombia, Sri-Lanka, Vietnam, and the USA, indicating that it is widespread in Asia, and South and North America [118].

Table 2 Serological surveys of Toxoplasma gondii infection in pregnant women during 1996 to 2008 in China

\begin{tabular}{|c|c|c|c|c|c|c|}
\hline Year & Age group & Area and Province & Serologic test $^{a}$ & No. tested & Positive & Reference \\
\hline 1996 & NA & Nanning, Guangxi & $\mathrm{IHA}$ & 1495 & $7.0 \%$ & {$[97]$} \\
\hline 1999-2002 & NA & Huainan, Anhui & ELISA & 228 & $10.1 \%$ & {$[98]$} \\
\hline 2003 & $20-39$ & Haerbin, Heilongjiang & ELISA & 2184 & $2.2 \%$ & [99] \\
\hline 2003 & NA & Nanchang, Jiangxi & ELISA & 298 & $6.0 \%$ & {$[100]$} \\
\hline 2000-2004 & $21-37$ & Chongqing & ELISA & 1820 & $0.8 \%$ & {$[101]$} \\
\hline $2002-2003$ & NA & Hongkou, Shanghai & ELISA & 1075 & $3.3 \%$ & {$[102]$} \\
\hline 2003-2004 & $23-45$ & Quanzhou, Fujian & ELISA & 550 & $2.7 \%$ & {$[103]$} \\
\hline 2000-2005 & $19-44$ & Guangzhou, Guangdong & ELISA & 1332 & $25.5 \%$ & [104] \\
\hline 2005 & $20-35$ & Jilin, Jilin & ELISA & 196 & $9.7 \%$ & {$[105]$} \\
\hline 2003-2006 & NA & Wenling, Zhejiang & $\mathrm{IBT}$ & 2425 & $0.5 \%$ & {$[106]$} \\
\hline 2004-2006 & NA & Baoding, Hebei & ELISA & 3500 & $3.6 \%$ & {$[107]$} \\
\hline 2005-2006 & NA & Guizhou & ELISA & 769 & $16.5 \%$ & {$[108]$} \\
\hline 2001-2007 & NA & Wuhan, Hubei & ELISA & 18127 & $13.2 \%$ & {$[109]$} \\
\hline 2007-2008 & NA & Kunshan, Jiangsu & ELISA & 1491 & $7.9 \%$ & {$[110]$} \\
\hline 2008 & $21-41$ & Linqing, Shandong & PM & 3559 & $5.0 \%$ & {$[111]$} \\
\hline 2008 & $18-45$ & Tongliao, Inner Mongolia & ELISA & 172 & $15.1 \%$ & {$[112]$} \\
\hline
\end{tabular}

NA: data were not available.

${ }^{a}$ ELISA: enzyme-linked immunosorbent assay, IHA: indirect hemagglutination test, IBT: immunoblotting test, PM: Protein microarray. 


\section{Conclusion}

\section{Suggested control strategies and measures}

The control of human toxoplasmosis is dependent on the reduction or elimination of the transmission of the parasite. However, the effective control of toxoplasmosis is still a difficult task in China. As the oral route is the major method of infection, efforts should be undertaken to guarantee the successful implementation of food safety regulations and regulatory control procedures. The Hazard Analysis and Critical Control Points (HACCP) principles [119], recommended by the Food and Agriculture Organization and WHO to be applied to control food-borne parasite infections in humans, should be evaluated by relevant Chinese authorities by relating to the actual conditions in China. Promoting educational programs directed at reducing environmental contamination with $T$. gondii would eventually reduce the cost of treating humans for clinical toxoplasmosis. There should also be educational programs to guide people to change their habit of consuming uncooked meat and unboiled water, for oocysts can survive for up to 3 years and be transmitted by water through direct drinking [120]. Rules for inspecting meat for $T$. gondii contamination before being sold should be set up and supported by governments.

Detection of antibodies is very important for pregnant women and women of child-bearing age. This is an effective way to find the infection, and then to provide treatment. It is also an efficient way to stop congenital toxoplasmosis in newborns. Good animal husbandry practice and animal welfare should be set up and popularized for food-producing animals, which may also decrease the risk of human infection. If such strategies and measures can be implemented, it should be possible to effectively control, or at least substantially reduce, the prevalence and intensity of human and animal infections with T. gondii in China.

\section{Acknowledgements \\ Project support was provided, in part, by the National Basic Research Program (973 program) of China (Grant No. 2010CB530001), National Natural Science Foundation of China (Grant Nos. 31172316 and 31101812 ), State Key Laboratory of Veterinary Etiological Biology, Lanzhou Veterinary Research Institute, Chinese Academy of Agricultural Sciences (Grant Nos. SKLVEB2009KFKT014, SKLVEB2010KFKT010 and SKLVEB2011KFKT004) and the Yunnan Provincial Program for Introducing High-level Scientists (Grant No. 2009(1125). Prof. J. P. Dubey at Animal Parasitic Diseases Laboratory, Animal and Natural Resources Institute, Beltsville Agricultural Research Center, United States Department of Agriculture, USA, and Assoc. Prof. Chunlei Su at Department of Microbiology, the University of Tennessee, Knoxville, USA are gratefully thanked for reading the draft manuscript and for providing constructive comments and suggestions.}

\section{Author details}

${ }^{1}$ State Key Laboratory of Veterinary Etiological Biology, Key Laboratory of Veterinary Parasitology of Gansu Province, Lanzhou Veterinary Research Institute, Chinese Academy of Agricultural Sciences, Lanzhou, Gansu Province 730046, P R China. ' Key Laboratory of Animal Parasitology of Ministry of Agriculture, Shanghai Veterinary Research Institute, Chinese Academy of
Agricultural Sciences, Shanghai 200241, P R China. ${ }^{3}$ Department of Parasitology, College of Veterinary Medicine, South China Agricultural University, Guangzhou, Guangdong Province 510642, P R China. ${ }^{4}$ Department of Pig Infectious Diseases, Shanghai Veterinary Research Institute, Chinese Academy of Agricultural Sciences, Shanghai 200241, P R China. ${ }^{5}$ Department of Parasitology, Shandong University School of Medicine, Jinan, Shandong Province 250012, P R China. ${ }^{6}$ College of Animal Science and Veterinary Medicine, Heilongjiang Bayi Agricultural University, Daqing, Heilongjiang Province 163319, P R China. ${ }^{7}$ College of Animal Science and Technology, Yunnan Agricultural University, Kunming, Yunnan Province 650201, P R China.

\section{Authors' contributions}

$X Q Z$ and $P Z$ conceived and designed the review, and critically revised the manuscript. PZ drafted the manuscript. ZC, HLL, HZ, SH and RQL contributed to drafting the manuscript. All authors read and approved the final manuscript.

\section{Competing interests}

The authors declare that they have no competing interests.

Received: 2 June 2011 Accepted: 24 August 2011

Published: 24 August 2011

\section{References}

1. Tenter AM, Heckeroth AR, Weiss LM: Toxoplasma gondii: from animals to humans. Int J Parasitol 2000, 30:1217-1258.

2. Dubey JP, Jones JL: Toxoplasma gondii infection in humans and animals in the United States. Int J Parasitol 2008, 38:1257-1278.

3. Alvarado-Esquivel C, Estrada-Martínez S: Toxoplasma gondii infection and abdominal hernia: evidence of a new association. Parasit Vectors 2011, 4:112.

4. Montoya JG, Liesenfeld O: Toxoplasmosis. Lancet 2004, 363:1965-1976.

5. Dubey JP: Toxoplasmosis of Animals and Humans. CRC Press, Second 2010.

6. Xie TH: A case report of human toxoplasmosis. Jiangxi Med J 1964, 4:121-212, (in Chinese).

7. Chen XG, Wu K, Lun ZR: Toxoplasmosis researches in China. Chin Med J 2005, 118:1015-1521.

8. Quan HY: Clinical analysis of 38 AIDS cases. Contemporary Med 2006, 11:85-86, (in Chinese).

9. Xia W, Zhang XJ, Chen XW: Investigation of different pregnant results of pregnant women infected with Toxoplasma gondii in Nanjing city. Chin J Schisto Control 2011, 23:183-186, (in Chinese).

10. Li JM, Chang XR, Ge QL: Investigation on infection of Toxoplasma gondii in 604 cases with mental diseases. Chin J Parasit Dis Con 2002, 15:150, (in Chinese).

11. Zhou P, Chen N, Zhang RL, Lin RQ, Zhu XQ: Food-borne parasitic zoonoses in China: perspective for control. Trends Parasitol 2008, 24:190-196.

12. Yu SH, Xu LQ, Jiang ZX, Xu SH, Han JJ, Zhu YG, Chang J, Lin JX, Xu FN: Report on the first national wide survey of the distribution of human parasites in China I: Regional distribution of parasite species. Chin J Parasitol Parasit Dis 1994, 12:241-247, (in Chinese).

13. Xiao Y, Yin JG, Jiang N, Xiang M, Hao LL, Lu HJ, Sang H, Liu XY, Xu HJ, Ankarklev J, Lindh J, Chen QJ: Seroepidemiology of human Toxoplasma gondii infection in China. BMC Infect Dis 2010, 10:4.

14. Darrel OHY: Toxoplasmosis. Medicine 2009, 37:665-667.

15. Xu LQ, Chen YD, Sun FH, Cai L, Fang YY, Wang LP, Liu X, Li LS, Feng Y, Li H: A national survey on current status of the important parasitic diseases and control strategies. Chin J Parasitol Parasit Dis 2005, 23:332-340, (in Chinese).

16. Dong $Y$, Zhang $Z X$ : A review of human parasitic disease prevalence in Yunan Province, China. J Pathogen Biol 2009, 4:626-632.

17. Li XM, Ouyang Y, Yang YC, Lin R, Xu HB, Xie ZY, Li SL, Shang SM: Distribution of food-borne parasitic diseases and dietary habits in human population in Guangxi. Chin J Parasitol Parasit Dis 2009, 27:151-152.

18. Liu Q, Yuan ZG, Gao SY, Liu B, Liu XF: Detection of antibody IgG against Toxoplasma gondii from pregnant/parturient women and cancer patients in Changchun region. J Pathogen Biol 2008, 3:122-123, (in (hinese). 
19. Yang ZJ, Wang CB, Hou XF: Analysis of Toxoplasma gondii infection in patients with malignant tumor. J Henan Oncol 2001, 14:135-136, (in Chinese).

20. Cheng YZ, Li ZE, Dong ZX, Li FY: Studies on susceptibility of leukemia patients to infection with Toxoplasma gondii and its clinical value. Chin J Parasit Dis Con 2001, 14:188-189, (in Chinese).

21. Zhang GL, Wang XY, Lai ZH: Serological detection of Toxoplasma gondii infection in patients with lung tuberculosis. Bull Chin Assoc Antituberculosis 2004, 26:118-119, (in Chinese).

22. Yuan WY: Investigation of Toxoplasma gondii infection in patients with hepatitis B. Chin J Parasit Dis Con 2002, 15:12, (in Chinese).

23. Baiomy AM, Mohamed KA, Ghannam MA, Shahat SA, Al-Saadawy AS: Opportunistic parasitic infections among immunocompromised Egyptian patients. J Egypt Soc Parasitol 2010, 40:797-808.

24. Shin DW, Cha DY, Hua QJ, Cha GH, Lee YH: Seroprevalence of Toxoplasma gondii infection and characteristics of seropositive patients in general hospitals in Daejeon, Korea. Korean J Parasitol 2009, 47:125-130.

25. Araujo FG, Remington JS: Toxoplasmosis in immunocompromised patients. Eur J Clin Microbiol 1987, 6:1-2.

26. Wang NF: The first case of AIDS reported in China mainland. J Chin Med 1991, 71:671, (in Chinese).

27. Zhou M, Huang $X$, Ku DRT: Infection of toxoplasmosis combining with HIV in the population of Xinjiang province. Chin J Zoon 2001, 17:127, (in Chinese).

28. Su Y, Zhao QX: Clinical analysis of AIDS cases complicated by toxoplasmic encephalitis. Chin J Practical Neruous Dis 2006, 9:85-86, (in Chinese).

29. Cao YH, Zhang XG, LV Q: Treatment analysis of 33 AIDS cases complicated with lymph node infections. Internal Med Chin 2007, 2:942-943, (in Chinese).

30. Goldenberg RL, Thompson C: The infectious origins of stillbirth. Am J Obstet Gynecol 2003, 189:861-873.

31. Gibbs RS: The origins of stillbirth: infectious diseases. Semin Perinatol 2002, 26:75-78.

32. Chen $\mathrm{CZ}, \mathrm{Pu}$ JZ: Investigation of infection of TORCH in neonate. Maternal Child Health Care China 2007, 22:3099-3100, (in Chinese).

33. Han MJ, Li YJ, Li XH, Zhang D: Study on status of Toxoplasma infection and immunology detection in new-born babies in Dalian region. Chin J Public Health 2005, 21:178-179, (in Chinese).

34. Zhou X, Fu JX, Ye HM: Research and analysis on TORCH infection in neonate in Huizhou. J Practical Med Tech 2007, 14:2148-2149, (in Chinese).

35. Tao GE, Liu SG, Chen JY: Analysis of IgG against Toxoplasma in cord blood serum from puerperals and neonate in Xinxiang city. J App/ Clin Pediatr 2003, 18:762, (in Chinese).

36. Zhou YH, Song LM, Jiang ZQ, Zhao SQ, Wu J, Gao QF, Shen YQ, Huang CY, Wang CG: Serological survey of Toxoplasma gondii infection in invalid children. Chin J Zoon 2002, 18:129-130, (in Chinese).

37. Huang MJ, Fang YH, Rong HQ: Study on the relationship between infantile cerebral palsy and toxoplasmosis. Chin Trop Med 2001, 1:33-34, (in Chinese).

38. Montoya JG, Remington JS: Toxoplasmic chorioretinitis in the setting of acute acquired toxoplasmosis. Clin Infect Dis 1996, 23:277-282.

39. Mets MB, Holfels E, Boyer KM, Swisher CN, Roizen N, Stein L, Stein M, Hopkins J, Withers S, Mack D, Luciano R, Patel D, Remington JS, Meier P, McLeod R: Eye manifestations of congenital toxoplasmosis. Am J Ophthalmol 1997, 123:1-16.

40. Gaddi PJ, Yap GS: Cytokine regulation of immunopathology in toxoplasmosis. Immunol Cell Biol 2007, 85:155-159.

41. Chen QJ, Neng HF, Wang JT, Xu XP, Ding ZY: Serology investigation on Toxoplasma infection in 103 ophthalmocace cases. Chin J Zoonoses 1991, 5:2-3, (in Chinese).

42. Liang $\mathrm{JH}$ : Report of 15 patients with ocular toxoplasmosis. Chin Trop Med 2008, 8:598-599, (in Chinese).

43. Hu SX, Yan H, Wei ZY, Li M, Xie CF, Lin SC, Zhang Y: Clinical observation of simultaneous FFA and IGGA in ocular toxoplasmosis. Chin Ophthal Res 2003, 21:511-514, (in Chinese).

44. Torrey EF, Yolken RH: Schizophrenia and toxoplasmosis. Schizophr Bull 2007, 3:727-728.

45. Pedersen MG, Stevens H, Pedersen CB, Norgaard-Pedersen B, Mortensen PB: Toxoplasma infection and later development of Schizophrenia in mothers. Am J Psychiatry 2011, 168:814-821.
46. Alvarado-Esquivel C, Urbina-Alvarez JD, Estrada-Martinez S, TorresCastorena A, Molotla-de-Leon G, Liesenfeld Q, Dubey JP: Toxoplasma gondii infection and schizophrenia: a case control study in a low Toxoplasma seroprevalence Mexican population. Parasitol Int 2011, 60:151-155.

47. Hamidinejat $H$, Ghorbanpoor M, Hosseini H, Alavi SM, Nabavi L, Jalali MH, Borojeni MP, Jafari H, Mohammadaligol S: Toxoplasma gondii infection in first-episode and inpatient individuals with schizophrenia. Int J Infect Dis 2010, 14:e978-981.

48. Brown AS, Schaefer CA, Quesenberry CP Jr, Liu L, Babulas VP, Susser ES: Maternal exposure to toxoplasmosis and risk of schizophrenia in adult offspring. Am J Psychiatry 2005, 162:767-773.

49. Huber M, Kirchler E, Karner M, Pycha R: Delusional parasitosis and the dopamine transporter. A new insight of etiology? Med Hypotheses 2007, 68:1351-1358.

50. Skallova A, Kodym P, Frynta D, Flegr J: The role of dopamine in Toxoplasma induced behavioural alterations in mice: An ethological and ethopharmacological study. Parasitology 2006, 133:525-535.

51. Krishnan RR, Keefe R, Kraus M: Schizophrenia is a disorder of higher order hierarchical processing. Med Hypotheses 2009, 72:740-744.

52. Berdoy $M$, Webster JP, Macdonld DW: Fatal attraction in rats infected with Toxoplasma gondii. Proc R Soc Lond B Biol Sci 2000, 267:1591-1594.

53. Sun SX, Li YJ, Fang F: Investigation on Toxoplasma gondii infection in mental disease cases from Dalian city. Chin J Parasit Dis Con 2005, 18:157, (in Chinese)

54. Chen YX, Lin J, Zhang JF, Luo SJ, Yu L, Chen JF: Toxoplasma infection and childhood schizophrenia. Med J Chin Civil Administration 2001, 13:199-200, (in Chinese).

55. Wang HL, Li QY, Wang GH, Shu C, Wang XP, Liu H, Duan JL, Yang XS: Survey on Toxoplasma infection in first-episode schizophrenia and its influence on the clinical manifestation of schizophrenia. Chin J Psychiatry 2005, 38:134-137, (in Chinese).

56. Wang HL, Wang GH, Li QY, Shu C, Wang XP, Wu JH: Clinical features of first-episode schizophrenic patients with and without anti-Toxoplasma IgG. Chin Mental Health J 2006, 20:40-42, (in Chinese).

57. Zhu SY, Lin YQ, Wang SQ, Xu SE: Contrast study on schizophrenia's toxoplasmosis infection rate. Med J Chin People Health 2003, 15:405-406, (in Chinese).

58. Stahl W, Kaneda Y, Noguchi T: Reproductive failure in mice chronically infected with Toxoplasma gondii. Parasitol Res 1994, 80:22-27.

59. Antonios SN, Ismail HI, Essa T: Hypothalamic origin of reproductive failure in chronic experimental toxoplasmosis. J Egypt Soc Parasitol 2000, 30:593-599.

60. Zhang C, Wang XC: Analysis and detection of infection of Toxoplasma gondii in infertile females from 2001 to 2006. J Henan Univ Sci Tech (Med Sci) 2007, 25:143-144, (in Chinese).

61. Gong TX, Li H, Lu NN: Analysis of pathogen infections in abnormal pregnancy women of child-bearing age in Xining area. Modern Prev Med 2006, 33:1969, (in Chinese).

62. Wei M, Jing DX, Luo RY, Zhang W, Wu XZ, Yang LD, Chen CY, Lu M: Study on the relationship between toxoplasmosis and oviducal sterility. J Pub Health Prev Med 2005, 16:31, (in Chinese).

63. Terpsidis KI, Papazahariadou MG, Taitzoglou IA, Papaioannou NG, Georgiadis MP, Theodoridis IT: Toxoplasma gondii: reproductive parameters in experimentally infected male rats. Exp Parasitol 2009, 121:238-241.

64. Yang LD, Chen CY, Lu M, Wu XZ, Gong F: Infertility experiment on male mice infected with Toxoplasma. Chin J Zoonoses 2005, 21:592-594, (in Chinese).

65. Zhou YH, Lu YJ, Wang RB, Song LM, Shi F, Gao QF, Luo YF, Guo XF, Wang P: Survey on infection of Toxoplasma gondii in infertile couples in Suzhou countryside. National J Androl 2002, 8:350-352, (in Chinese).

66. Qi R, Su XP, Gao XL, Liang XL: Study on Toxoplasma infection in males with sterility in Shenyang city. National J Andrology 2005, 11:503-504, (in Chinese).

67. Yue L, Wang LF, Chen SM: Study on the interrelationship between Toxoplasma gondii infection and male sterility. Shaanxi Med J 2006, 35:1138-1140, (in Chinese).

68. Hui QF, Jiang CX, Cui $Y X, A i C L, X u$ YJ: Detection Ig $G$ and Ig $M$ antibodies against Toxopalsma in sera of males with sterility. J Yanan Univ (Med Sci) 2003, 1:85-86, (in Chinese). 
69. Lu S: Male infertility caused by Toxoplasma. National J Androl 1998, 4:269-270, (in Chinese).

70. Lin $A Q$, Zhong WZ, Sun B, Ma ZQ: Serological investigation of CAg, IgM and $\lg$ to $T$. gondii in workers in slaughter farms from Haerbin. Chin J Zoonoses 2003, 19:130, (in Chinese).

71. Chen ZY, Li AM, Lin GC, Wang XZ: Serological investigation of Toxoplasma infection among different populations of people in Guizhou Province. Acta Academiae Med Zunyi 2005, 28:382-383, (in Chinese).

72. Feng YJ, Liu XN, Ren WF, Pan ZM, Gao YP, Guo RT: Analysis of serological investigation for Toxoplasma in Guangzhou city in 2004. J Trop Med 2005, 5:830-832, (in Chinese).

73. Liang ZB, Feny YJ, Li K, Lu HX, Shen QF: Serological investigation of Toxoplasma gondii in Huadu district in 2004. J Trop Med 2006, 6:448-449, (in Chinese).

74. Zhang Y, Li H: Seroepidemiological investigation of Toxoplasma gondii infection among population in Lanzhou area. Chin J Parasit Dis Con 2005, 18:432-433, (in Chinese).

75. Yang SN, You SF, Xu ZH, Yu CE: Serological investigation on antibody against Toxoplasma gondii for service trade workers in Wuxi city during 1996 to 1999. Practical Prev Med 2004, 11:506-507, (in Chinese).

76. Zou FC, Sun XT, Xie YJ, Li B, Zhao GH, Duan G, Zhu XQ: Seroprevalence of Toxoplasma gondii in pigs in southwestern China. Parasitol Int 2009, 58:306-307.

77. Zhou DH, Liang R, Yin CC, Zhao FR, Yuan ZG, Lin RQ, Song HQ, Zhu XQ: Seroprevalence of Toxoplasma gondii in pigs from southern China. $J$ Parasitol 2010, 96:673-674.

78. Yu H, Zhang Z, Liu Z, Qu D, Zhang D, Zhang H, Zhou Q, Du A: Seroprevalence of Toxoplasma gondii infection in pigs, in Zhejiang Province, China. J Parasitol 2011, 97:748-749.

79. Hill DE, Haley C, Wagner B, Gamble HR, Dubey JP: Seroprevalence of and risk factors for Toxoplasma gondii in the U.S. swine herd using sera collected during the National Animal Health Monitoring Survey (Swine 2006). Zoonosis Public Health 2010, 57:53-59.

80. de Buhr K, Ludewig M, Fehlhaber K: Toxoplasma gondii-seroprevalence current results in German swine herds. Arch Lebensmittelhyg 2008, 59:5-8.

81. Alvarado-Esquivel C, Garcia-Machado C, Alvarado-Esquivel D, GonzalezSalazar AM, Briones-Fraire C, Vitela-Corrales J, Villena I, Dubey JP: Seroprevalence of Toxoplasma gondii infection in domestic pigs in Durango State, Mexico. J Parasitol 2011, 97:616-619.

82. Seuri M, Koskela P: Contact with pigs and cats associated with high prevalence of Toxoplasma antibodies among farmers. Brit J Ind Med 1992, 49:845-849.

83. Ibrahim BB, Salama MM, Gawish NI, Haridy FM: Serological and histopathological studies on Toxoplasma gondii among the workers and the slaughtered animals in Tanta Abattoir, Gharbia Governorate. J Egypt Soc Parasit 1997, 27:273-278.

84. Dias RA, Navarro IT, Ruffolo BB, Bugni FM, Castro MV, Freire RL: Toxoplasma gondii in fresh pork sausage and seroprevalence in butchers from factories in Londrina, Paraná State, Brazil. Rev Inst Med Trop Sao Paulo 2005, 47:185-189.

85. Alvarado-Esquivel C, Liesenfeld O, Estrada-Martinez S, Felix-Huerta J: Toxoplasma gondii infection in workers occupationally exposed to raw meat. Occup Med (Lond) 2011, 61:265-269.

86. Huo SL, Song ZZ, Zhang B, Li X, Han S, Bai L, Wu CP: Serological epidemiological survey of Toxoplasma gondii infection in humans in Inner Mongolia Autonomous Region. Med Anim Prev 2007, 23:894-896, (in Chinese).

87. Huang $X$, Zhang GM, Zhao HZ: Reviews on studies of toxoplasmosis in Xijiang during 1990 to 2000. Endemic Dis Bull 2001, 16:98-99, (in Chinese).

88. Zhao LQ, Liu SQ: Serological surveillance of Toxoplasma infection in Haizhu district in 2004. J Trop Med 2007, 7:495-496, (in Chinese).

89. Castagnini M, Bernazzali S, Ginanneschi C, Marchi B, Maccherini M, Tsioulpas C, Tanganelli P: Fatal disseminated toxoplasmosis in a cardiac transplantation with seropositive match for Toxoplasma: Should prophylaxis be extended? Transpl Immunol 2007, 18:193-197.

90. Ye DQ, Hao JH, Huan GF, Yu XB: Study on sero-indexes among 2690 qualified blood donors. Chin J Public Health 2003, 19:454-455, (in Chinese).

91. Zhu XM, Yang TH, Yang GQ, Zhao Y, Tu YQ, He Y, Yao FZ: Study on Toxoplasma gondii infection in blood donors of Yunnan Province. $J$ Clin Transfus Lab Med 2007, 9:295-298, (in Chinese).
92. Elsheikha HM, Aboul-Dahab MA, Abdel Maboud Al, El-Sherbini ET: Prevalence and risk factors of Toxoplasma gondii antibodies in asymptomatic Egyptian blood donors. J Egypt Soc Parasitol 2009, 39:351-361.

93. Nissapatorn V, Kamarulzaman A, Init I, Tan LH, Rohela M, Norliza A, Chan LL, Latt HM, Anuar AK, Quek KF: Seroepidemiology of toxoplasmosis among HIV-infected patients and healthy blood donors. Med J Malaysia 2002 57:304-310.

94. Jin ZS, Feng ZB, Dai HD, Li JR: Study of Toxoplasma infection among intravenous drug users and the affecting factors. Central Chin Med J 2006, 30:489-490, (in Chinese).

95. Chen GX: Investigation of Toxoplasma infection among male intravenous drug users. J Practical Med 2004, 20:966, (in Chinese).

96. Mitchell CD, Erlich SS, Mastrucci MT, Hutto SC, Parks WP, Scott GB: Congenital toxoplasmosis occurring in infants perinatally infected with human immunodeficiency virus 1. J Pediatr Infect Dis 1990, 9:512-518.

97. Su CK, Wu ZB: Epidemiological characteristics of Toxoplasma gondii infection in married women of childbearing age in Nanning city. $J$ Guangxi Med Univ 2002, 19:88, (in Chinese).

98. Lu J: Serological survey of Toxoplasma infection among pregnant women in Huainan area. J Trop Dis Parasitol 2004, 2:159-160, (in Chinese).

99. Li SF, Zhao CH, Zhang R, Sun DL: Investigation of antibody lgM against TORCH in pregnant women by MAC-ELISA in Haerbin area. Heilongjiang Med J 2003, 16:234, (in Chinese).

100. Chen HY, Xiao HM, Zeng XJ, Xiong CH, Ge J, Hu GH: Seroepidemiologic investigation of Toxoplasma gondii infection among population in Nanchang area. Chin J Parasit Dis Con 2005, 18:436-437, (in Chinese).

101. Yue $X L$, Ding $X P$, Ren $Y Q$, Zhang L: Clinical observation on TORCH infection of pregnant women in Chongqing area. Chin J Birth Health Heredity 2005, 13:83-84, (in Chinese).

102. Jiang SY, Bian HZ, Yang Y, Zhou HJ, Zhou JH, Lu Z: Survey of Toxoplasma gondii infection in pregnant women in Hongkou district, Shanghai city. Shanghai J Prev Med 2005, 17:210-212, (in Chinese).

103. Fan CM, Fan HQ: Survey of TORCH infection in married women of childbearing age in Quanzhou city during April, 2003 to March, 2004. Fujian Med J 2005, 27:140, (in Chinese).

104. Zhong YF, Xue SH: Prevalence of TORCH-lgG antibodies in nonvaccinated married fertile-aged women in Guangzhou. Maternal Child Health Care China 2006, 21:3309-3310, (in Chinese).

105. Liu B, Wu M: Experimental study of Toxoplasma infection among pregnant women in Jilin Area. J Beihua Univ (Nat Sci) 2005, 6:526-527, (in Chinese).

106. Cheng ML, Wang J, Wu F: Investigation of infection of TORCH in the pregnancy in Wenlin city. J Clin Exp Med 2006, 5:993, (in Chinese).

107. Li W: Survey of Toxoplasma gondii infection in pregnant women in Baoding. Chin J Birth Health Heredity 2007, 15:65-66, (in Chinese).

108. Tang LN, Xu LN, Lu LD, Li AM, Zhou GR, Lin GC: Serological survey and evaluation of Toxoplasma infection in pregnant women in Guizhou province. Guizhou Med J 2007, 31:847-848, (in Chinese).

109. Suo QL, Yao T: Research on Toxoplasma gondii infection in pregnancy in Wuhan city. Maternal Child Health Care China 2009, 24:598-599, (in Chinese).

110. Ji JF, Luo XM, LV GM: Serological detection of IgG and IgM against Toxoplamsa gondii in 1491 pregnant women. Contemporary Med 2009, 15:157, (in Chinese).

111. Liu XX: Analysis of Toxoplasma gondii infection in 3559 married women of childbearing age. Shandong Med J 2009, 49:107, (in Chinese).

112. Han M, Huo WX, Zhang DL, Zhang Y, Zhang WQ: Serosurvey of Toxoplasma gondii infection in fertile women in Tongliao city. J Pathogen Biol 2009, 4:478-479, (in Chinese).

113. Edelhofer R, Prossinger $H$ : Infection with Toxoplasma gondii during pregnancy: seroepidemiological studies in Austria. Zoonoses Public Health 2010, 57:18-26.

114. Berger F, Goulet V, Le Strat Y, Desenclos JC: Toxoplasmosis among pregnant women in France: risk factors and change of prevalence between 1995 and 2003. Rev Epidemiol Sante Publique 2009, 57:241-248.

115. Vaz RS, Thomaz-Soccol V, Sumikawa E, Guimaraes AT: Serological prevalence of Toxoplasma gondii antibodies in pregnant women from Southern Brazil. Parasitol Res 2010, 106:661-665. 
116. Zhou P, Zhang H, Lin RQ, Zhang DL, Song HQ, Su C, Zhu XQ: Genetic characterization of Toxoplasma gondii isolates from China. Parasitol Int 2009, 58:193-195.

117. Dubey JP, Zhu XQ, Sundar N, Zhang H, Kwok OC, Su C: Genetic and biologic characterization of Toxoplasma gondii isolates of cats from China. Vet Parasitol 2007, 145:352-356.

118. Zhou P, Nie H, Zhang LX, Wang HY, Yin CC, Su C, Zhu XQ, Zhao JL: Genetic characterization of Toxoplasma gondii isolates from pigs in China. $J$ Parasitol 2011, 96:1027-1029.

119. Hulebak KL, Schlosser W: Hazard analysis and critical control point (HACCP) history and conceptual overview. Risk Anal 2002, 22:547-552.

120. Dubey JP: Toxoplasmosis - a waterborne zoonosis. Vet Parasitol 2004, 126:57-72.

doi:10.1186/1756-3305-4-165

Cite this article as: Zhou et al:: Toxoplasma gondii infection in humans

in China. Parasites \& Vectors 2011 4:165.

\section{Submit your next manuscript to BioMed Central} and take full advantage of:

- Convenient online submission

- Thorough peer review

- No space constraints or color figure charges

- Immediate publication on acceptance

- Inclusion in PubMed, CAS, Scopus and Google Scholar

- Research which is freely available for redistribution

Submit your manuscript at www.biomedcentral.com/submit
Ciomed Central 